\title{
The Role of Maternal Serum Triglycerides in Prediction of Large-For Gestational-Age in Pregestational and Gestational Diabetes Mellitus
}

\author{
Bassem A Islam ${ }^{1 *}$ and Walid Abdelhady ${ }^{2}$ \\ ${ }^{1}$ Department of Obstetrics and Gynecology, Ain Shams University, Egypt \\ ${ }^{2}$ Department of Clinical Pathology, Ain Shams University, Egypt
}

Submission: December 14, 2019; Published: January 07, 2020

*Corresponding author: Bassem A Islam, Department of Obstetrics and Gynecology, Ain Shams University, Egypt

\begin{abstract}
Introduction: Still there is increasing tendency to macrosomia in fetuses of diabetic women despite good diabetic control. Hyperglycemia is not only the responsible factor of undue fetal weight in pregnant women. The study intent was to find out whether maternal hyperlipidemia is responsible for prevalence of large for gestational age (LGA) in newborns of women with pregestational (PGDM) and gestational diabetes (GDM).

Material and methods: This prospective observational, single-center study was executed in women with PGDM and GDM. The study was held in Ain Shams University Maternity Hospital. Data were gathered in the (35th-38th weeks).

Result: Among 216 pregnant women recruited in the analysis, 45 cases (20.8\%) delivered average-for-gestational-age (AGA) newborns, all of them delivered normally. The remaining 171 cases (79.2\%) newborns were large for gestational age (LGA), 100 of them were delivered by C.S and other 71 were delivered normally. The preponderance of LGA newborns was significantly higher in women with hypertriglyceridemia. Maternal TG and cholesterol levels were significantly higher in the group of LGA than in the AGA group $(374.73 \pm 103.16)$ vs $(242.23 \pm 88.99)$, $p=0.00$, and $(249.93 \pm 38.85)$ vs $(187.54 \pm 22.95), p<0.0001$ respectively. While HDL was significantly lower in the LGA group than in the AGA group (53.95 \pm 11.78 ) vs (66.61 \pm 9.01$)$, $\mathrm{p}<0.0001$. Maternal Cholesterol, HDL-C and triglycerides levels tended to be correlated with newborn birth weight with sensitivity $80 \%, 86.7 \%, 86.7 \%$, specificity $87.7 \%, 87.7 \%, 70.1 \%$ and cut off value $>213.5 \mathrm{mg} / \mathrm{dl},<61.3 \mathrm{mg} / \mathrm{dl},>345 \mathrm{mg} / \mathrm{dl} \mathrm{respectively}$.

Conclusion: Decreased serum HDL-C and increased serum triglycerides and cholesterol levels in pregnant women with PGDM and GDM might chip in the evolution of fetal macrosomia or LGA
\end{abstract}

Keywords: Pregestational and gestational diabetes; Pregnancy; Lipids; Large-for-gestational-age; Hypertriglyceridemia; Fetal macrosomia; Serum lipid metabolism; Insulin; Fetuses; Maternal nutrients; Glucose, Amino acids; Lipoproteins

\section{Introduction}

The magnitude of fetal macrosomia is significantly high in diabetic pregnant women. Distinction in neonatal weight that occur are not restricted only to the maternal glucose level, but also other metabolic factors such as lipids may have a remarkable role [14]. Serum lipid metabolism is somewhat altered during pregnancy in diabetic women with increased serum maternal lipoprotein concentrations because of increased insulin resistance and lipolysis of peripheral adipose tissue [5,6]. Obstetric complications such as preterm delivery and preeclampsia were more frequent with this abnormal metabolism of lipid. Furthermore, study of Freinkel et al. showed that "mixture" of maternal nutrients as (glucose, amino acids and lipoproteins) change the metabolic state of the fetuses, the fetal development and growth, also future obesity and development of diabetes in the progeny (fuel mediated-teratogenesis), and cardiovascular disease due to fetal programming [7]. Treatment of hyperlipidemia is a very important therapeutic target in non-pregnant diabetic settings. But are not recommended among diabetic pregnant women [8]. The intent of the current study was to assess the upshot of maternal lipids in the third trimester in predicting (large-for-gestational-age) macrosomic newborns in pregnant women with pregestational and gestational diabetes and if there is preventive measures may be taken such as prepregnancy management of hyperlipidemia and proper diabetic control. 


\section{The study intents are}

a) To ascertain the relevance between maternal lipids and newborns with large-for-gestational-age in diabetic pregnant women.

b) To check the predictive level of maternal triglycerides in predicting neonatal weight in diabetic pregnant women.

\section{Material and Methods}

This prospective study of pregnant diabetic women attended to antenatal clinic (ANC) and/or admitted to the maternity ward at Ain Shams University Maternity Hospitals (ASUH), Egypt, over the period from March 2016 till June 2018. Patients were recruited from Ain Shams Maternity clinic and ward admission in the hospital. Of the 251 diabetic women, 35 cases were excluded from the study due to missed abortion (10 cases), missed during follow up ( 9 cases), IUFD (4 cases), preterm labor ( 5 cases) and 7 cases refused participation. 216 diabetic pregnant women were included in the study and were eligible for the final analysis.

The study protocol was approved by ASUH Ethical Committee. Counseling of participating women, clear caption of the intervention, and an informed written consent was then taken from all of them. During the ANC visit enrolment, medical, past, surgical and obstetric histories were reviewed, general and abdominal examinations were carried out, FHR was checked, and findings were recorded. Estimation of gestational age (GA) was done from the date of LMP in women with prior regular periods or estimated from early ultrasound scan (USS) at 7 weeks' gestation. GA was verified by the 13 th week USS. Fetal anomaly scan was arranged at around 20 weeks' gestation. Then women were followed up as per the standard pregnancy care for diabetes where they attended every 2 weeks until 28 weeks' gestation, every 1 weeks until 36 weeks' gestation then twice weekly thereafter until delivery. Targeting a fasting glucose level of $60-100 \mathrm{mg} / \mathrm{dl}$, 1-hour postprandial glucose below $120 \mathrm{mg} / \mathrm{dl}$, and glycated hemoglobin (HbA1c) below 6.1\% (25). All women were on insulin therapy.

\section{Exclusion criteria}

a. Pregnancies with congenital anomalies.

b. Women with hypertension, thyroid or connective tissue disorders

c. Multifetal gestations.

d. Cases delivered before 35 weeks' gestation.

e. Postdate.

f. Uncontrolled diabetics.

g. Abnormal glycosylated hemoglobin (HbA1c) level, above $6.1 \%$.

h. IUGR.

i. $\quad B M I<30 \mathrm{~kg} / \mathrm{m} 2$. j. Past history of macrosomic baby.

k. Bad obstetric history.

\section{Cases are divided into two main groups}

Group A: Pregestational Diabetic women with type 1 or type 2 diabetes.

Group B: Pregnant women diagnosed with gestational diabetes mellitus (GDM). GDM was generally diagnosed by OGTT in the second half of pregnancy. The OGTT was performed in the morning after a nightlong fasting from 8 to $12 \mathrm{~h}$. The criteria for the diagnosing GDM were at least one abnormally high out of three plasma glucose value measurements during the $75 \mathrm{gm}$ OGTT (normal values: a fasting level $<92 \mathrm{mg} / \mathrm{dl}$, 1 -hour level $<180 \mathrm{mg} / \mathrm{dl}$, 2 -hour level $<153 \mathrm{mg} / \mathrm{dl}$ ). The venous blood glucose levels were measured using the glucose oxidase method (AU 480 Analyzer; Beckman Coulter, California, USA). The glucose tolerance was classified by the latest criteria of the International Association of Diabetes in Pregnancy Study Group (IADPSG) (9) by using the 75gm 2-hour oral glucose tolerance test (OGTT) at 24-28week gestation.

In the third trimester, the fasting maternal total cholesterol, triglycerides, high-density lipoprotein Cholesterol (HDL-C), lowdensity lipoprotein Cholesterol (LDL-C) were measured in both groups. The samples for lipids assessment were collected after the overnight fasting. Analysis of the lipoproteins blood samples was executed using AU 480 analyzer according to the standard methods. Total cholesterol and triglycerides were checked with the full enzymatic methods (Cholesterol Oxidae and triglyceridesGlycerol Phosphate Oxidase). HDL-C was measured using the polyanion precipitation method, while LDL was calculated using the Friedewald formula.

Blood samples were assembled after nightlong fasting and transported immediately to the laboratory of the Obstetric Gynecological University Hospital for analysis. The total serum cholesterol, HDL-C, LDL, and triglyceride (TG) levels were assessed with participation of the clinical pathology department in Ain Shams University. The level of low-density lipoprotein (LDL) cholesterol was calculated using Friedewald formula: LDL cholesterol $=$ Total cholesterol-(HDL cholesterol+(TG/5)) .

\section{Fetal investigations}

a) CTG.

b) Trans-abdominal ultrasound examination for fetal viability, gestational age confirmation, measurement of the fetal abdominal circumference (AC), and estimation of expected fetal birth weight (EFBW) immediately before delivery. Hospital admission of the patients will be at the time of delivery or if developed any complication of diabetes.

c) Neonatal birth weight is measured in grams upon delivery. 
d) Large-for-gestational-age fetuses are defined as those with birth weight above the 90th centile for age, and whose birth weight falling below 10th centile is defined as small-forgestational-age.

Mode of delivery will be according to hospital protocol.

\section{Statistical Analysis}

Data were collected from taken history, clinical examination, laboratory investigations, and outcome measured, entered and analyzed using Microsoft Excel software. Then data were submitted to Statistical Package for the Social Sciences software for analysis (SPSS version 20). According to the type of data, qualitative represented as number and percentage, quantitative represented by mean $\pm \mathrm{SD}$, the following tests were used to test the differences for significance; difference and association of qualitative variable by Chi-square test (X2), between quantitative parametric groups by t-test, non-parametric by Mann Whitney, correlation by Pearson's correlation and regression. P value was set at $<0.05$ for significant results $\&<0.001$ for high significant result.

Results: 216 diabetic women were eligible for the final analysis. The demographic criteria for studied groups shown in Table 1 with no significance among them. The mean, Serum triglycerides (TG) levels were found to be significantly higher in women with GDM $(248.83 \pm 114.2 \mathrm{mg} / \mathrm{dl})$, type $2 \mathrm{DM}$ women $(286.91 \pm 94.12 \mathrm{mg} / \mathrm{dl})$ and type $1 \mathrm{DM}(258.14 \pm 135.5)$ compared to controls $(180.7 \pm 10.8) \mathrm{mg} / \mathrm{dl}$. Similarly, Serum Cholesterol was significantly higher in women with GDM (199.11 \pm 35.09 ) $\mathrm{mg} / \mathrm{dl}$ and type $2 \mathrm{DM}$ women $(220.5 \pm 44.5) \mathrm{mg} / \mathrm{dl}$ and type $1 \mathrm{DM}$ $(274.8 \pm 50.3) \mathrm{mg} / \mathrm{dl}$ as compared with controls $(151.9 \pm 10.5) \mathrm{mg} /$ dl. Such a significance was also seen in the case of LDL-C, with the mean LDL-C being $(137.96 \pm 28.35) \mathrm{mg} / \mathrm{dl}$ in GDM, $(110.7 \pm$ $38.4) \mathrm{mg} / \mathrm{dl}$ in type $2 \mathrm{DM}$ and $(146 \pm 42.3) \mathrm{mg} / \mathrm{dl}$ in type1 DM. In contrast, HDL-C was significantly elevated in controls (47.1 \pm 3.7$)$ $\mathrm{mg} / \mathrm{dl}$, compared to GDM $(64.15 \pm 5.9) \mathrm{mg} / \mathrm{dl}$ and type $2 \mathrm{DM}$ women $(63.28 \pm 12.71) \mathrm{mg} / \mathrm{dl}$ and $(61.33 \pm 7)$ in type $1 \mathrm{DM}$ as in Table 2 . Among 216 women included in the analysis 45 cases (20.8\%) delivered AGA newborns and all of them delivered normally. The remaining 171 cases $(79.2 \%)$ delivered newborns with large-forgestational-age (LGA). 100 of them had delivered by C.S other 71 had delivered normally (Table 3). Women with GDM, 18 delivered AGA newborns, 63 delivered LGA newborns, in type 1 DM 6 cases delivered AGA newborns, 15 cases delivered LGA newborns, and in type 2 DM 21 cases delivered AGA newborns, 93 cases delivered LGA newborns.

Table 1: Socio-demographic data of the studied groups according to different types of $D M(N=216)$.

\begin{tabular}{|c|c|c|c|c|c|c|}
\hline & & $\mathbf{N}$ & Mean \pm S.D & Minimum & Maximum & $\mathbf{P}$ \\
\hline \multirow{3}{*}{ Age(years) } & GDM & 81 & $31.93 \pm 5.70$ & 23 & 40 & \multirow{3}{*}{$0.001^{* *}$} \\
\hline & Type 2 & 114 & $29.42 \pm 4.27$ & 20 & 35 & \\
\hline & Type 1 & 21 & $24.29 \pm 3.35$ & 19 & 28 & \\
\hline \multirow{3}{*}{$\operatorname{BMI}\left(\mathrm{kg} / \mathrm{m}^{2}\right)$} & GDM & 81 & $25.07 \pm 2.73$ & 28 & 40 & \multirow{3}{*}{0.426} \\
\hline & Type 2 & 114 & $27.39 \pm 3.45$ & 26 & 44 & \\
\hline & Type 1 & 21 & $31.71 \pm 2.36$ & 29 & 36 & \\
\hline \multirow{3}{*}{$\begin{array}{l}\text { Gest age at delivery } \\
\text { by LMP(week) }\end{array}$} & GDM & 81 & $36.37 \pm 1.24$ & 31 & 38 & \multirow{3}{*}{0.396} \\
\hline & Type 2 & 114 & $36.39 \pm 1.30$ & 30 & 38 & \\
\hline & Type 1 & 21 & $35.71 \pm 0.48$ & 35 & 36 & \\
\hline \multirow{3}{*}{ Gravidity } & GDM & 81 & $2.9 \pm 0.8$ & 1 & 3 & \multirow{3}{*}{0.3} \\
\hline & Type 2 & 114 & $2.6 \pm 0.4$ & 1 & 6 & \\
\hline & Type 1 & 21 & $2.5 \pm 0.48$ & 1 & 14 & \\
\hline \multirow{3}{*}{ Parity } & GDM & 81 & $1.3 \pm 0.2$ & 1 & 3 & \multirow{3}{*}{0.3} \\
\hline & Type 2 & 114 & $1.6 \pm 0.4$ & 1 & 2 & \\
\hline & Type 1 & 21 & $1.5 \pm 0.48$ & 1 & 2 & \\
\hline \multirow{3}{*}{ Abortion } & GDM & 81 & $0.3 \pm 0.05$ & 0 & 4 & \multirow{3}{*}{0.2} \\
\hline & Type 2 & 114 & $0.4 \pm 0.1$ & 1 & 10 & \\
\hline & Type 1 & 21 & $0.5 \pm 0.1$ & 1 & 13 & \\
\hline \multirow{3}{*}{ Fetal Weight by US } & GDM & 81 & $3525.19 \pm 596.38$ & 1900 & 4600 & \multirow{3}{*}{0.394} \\
\hline & Type 2 & 114 & $3443.50 \pm 525.07$ & 2300 & 4240 & \\
\hline & Type 1 & 21 & $3172.29 \pm 989.62$ & 1650 & 4400 & \\
\hline \multirow{3}{*}{ Neonatal birth weight } & GDM & 81 & $3711.11 \pm 514.66$ & 2000 & 4500 & \multirow{3}{*}{0.365} \\
\hline & Type 2 & 114 & $3718.42 \pm 446.52$ & 2500 & 4500 & \\
\hline & Type 1 & 21 & $3428.57 \pm 740.98$ & 2500 & 4500 & \\
\hline
\end{tabular}


Table 2: Lipid profile distribution according to types of D.M ( $n=216)$.

\begin{tabular}{|c|c|c|c|c|c|}
\hline & & Mean S.D & Minimum & Maximum & $\mathbf{P}$ \\
\hline \multirow{3}{*}{ TG in 3rd trimester } & GDM & $248.83 \pm 114.2$ & 93.3 & 494 & \multirow{3}{*}{0.351} \\
\hline & Type 2 & $286.91 \pm 94.12$ & 100 & 539.6 & \\
\hline & Type 1 & $258.14 \pm 135.5$ & 143.7 & 431 & \\
\hline \multirow{3}{*}{ HDL } & GDM & $64.15 \pm 9.33$ & 49 & 84 & \multirow{3}{*}{0.85} \\
\hline & Type 2 & $63.28 \pm 12.71$ & 32 & 84 & \\
\hline & Type 1 & $61.33 \pm 7.00$ & 50 & 70 & \\
\hline \multirow{3}{*}{ LDL } & GDM & $137.96 \pm 28.35$ & 95 & 195 & \multirow{3}{*}{0.898} \\
\hline & Type 2 & $110.7 \pm 38.4$ & 100 & 188 & \\
\hline & Type 1 & $146.0 \pm 42.3$ & 98 & 190 & \\
\hline \multirow{3}{*}{ Cholest } & GDM & $199.11 \pm 35.09$ & 145 & 295 & \multirow{3}{*}{0.969} \\
\hline & Type 2 & $220.5 \pm 44.5$ & 150 & 300 & \\
\hline & Type 1 & $274.8 \pm 50.3220 .5 \pm 44.5$ & 165 & 310 & \\
\hline
\end{tabular}

Table 3: Association between neonatal birth weight \& types of DM and mode of delivery.

\begin{tabular}{|c|c|c|c|c|c|c|}
\hline & & \multicolumn{2}{|c|}{ Neonatal weight } & \multirow{2}{*}{ Total } & \multirow{2}{*}{$\mathbf{X}^{2}$} & \multirow{2}{*}{$\mathbf{P}$} \\
\hline & & over No (\%) & Normal No (\%) & & & \\
\hline GDM & No (\%) & $63(29.2)$ & $18(8.3)$ & $81(37.5)$ & \multirow{4}{*}{0.42} & \multirow{4}{*}{0.81} \\
\hline Type 1 DM & No (\%) & $15(6.9)$ & $6(2.7)$ & $21(9.6)$ & & \\
\hline Type 2 DM & No (\%) & $93(43.05)$ & $21(9.7)$ & $114(52.8)$ & & \\
\hline Total & & $171(79.2)$ & $45(20.8)$ & $216(100)$ & & \\
\hline Delivery CS & No.(\%) & $100(46.2)$ & 0 & $100(46.2)$ & \multirow{2}{*}{6.31} & \multirow{2}{*}{$0.012^{*}$} \\
\hline VD & No.(\%) & $71(32.8)$ & $45(20.8)$ & $116(53.7)$ & & \\
\hline Total & No.(\%) & 171(79) & $45(20.8)$ & $216(100)$ & & \\
\hline
\end{tabular}

Table 4: Comparison between demographc data and lipid profiles in the studied groups in relation to neontal body weight.

\begin{tabular}{|c|c|c|c|c|}
\hline & Weight & Mean \pm S.D & t/ Mann Whitney & $\mathbf{P}$ \\
\hline \multirow{2}{*}{ Age(years) } & Over weight & $31.13 \pm 4.63$ & \multirow{2}{*}{1.065} & \multirow{2}{*}{0.291} \\
\hline & Within Normal & $29.53 \pm 5.34$ & & \\
\hline \multirow{2}{*}{ BMI(kg/m2) } & Over weight & $32.40 \pm 2.47$ & \multirow{2}{*}{$-0.996-$} & \multirow{2}{*}{0.322} \\
\hline & Within Normal & $33.29 \pm 3.25$ & & \\
\hline \multirow{2}{*}{ Gest age at delivery by LMP(week) } & Over weight & $36.60 \pm .83$ & \multirow{2}{*}{0.992} & \multirow{2}{*}{0.325} \\
\hline & Within Normal & $36.25 \pm 1.31$ & & \\
\hline \multirow{3}{*}{$\mathrm{TG}(\mathrm{mg} / \mathrm{dl})$} & Over weight & $374.73 \pm 103.16$ & \multirow{3}{*}{4.963} & \multirow{3}{*}{$0.00^{* *}$} \\
\hline & Within Normal & $242.23 \pm 88.99$ & & \\
\hline & Within Normal & $152.16 \pm 55.39$ & & \\
\hline \multirow{2}{*}{$\mathrm{HDL}(\mathrm{mg} / \mathrm{dl})$} & Over weight & $53.95 \pm 11.78$ & \multirow{2}{*}{-4.334} & \multirow{2}{*}{$0.00^{* *}$} \\
\hline & Within Normal & $66.61 \pm 9.01$ & & \\
\hline \multirow{2}{*}{ Cholesterol(mg/dl) } & Over weight & $249.93 \pm 38.85$ & \multirow{2}{*}{7.995} & \multirow{2}{*}{$0.00^{* *}$} \\
\hline & Within Normal & $187.54 \pm 22.95$ & & \\
\hline \multirow{2}{*}{$\mathrm{LDL}(\mathrm{mg} / \mathrm{dl})$} & Over weight & $156.90 \pm 32.30$ & \multirow{2}{*}{2.147} & \multirow{2}{*}{0.051} \\
\hline & Within Normal & $126.76 \pm 22.39$ & & \\
\hline
\end{tabular}




\section{Journal of Gynecology and Women's Health}

Table 5: Area under the Curve for Cholesterol, HDL \& TG.

\begin{tabular}{|c|c|c|c|c|c|c|c|}
\hline Test Result Variable(S) & Area & Cutoff & Sensitvity & Specificity & \multicolumn{2}{|c|}{ 95\% Confdeince Interval } \\
\hline Cholesterol & 0.908 & $>213.5$ & $86.70 \%$ & $87.70 \%$ & 0 & 0.804 & 1 \\
\hline HDL & 0.832 & $<61.3$ & $86.70 \%$ & $70.10 \%$ & 0 & 0.035 & 0.316 \\
\hline TG & 0.817 & $>345$ & $80 \%$ & $87.70 \%$ & 0 & 0.665 & 0.97 \\
\hline
\end{tabular}

Table 6: shows Significant association and agreement between overweight cutoff regarding TG, Cholesterol and HDL.

\begin{tabular}{|c|c|c|c|c|c|c|c|c|}
\hline & \multicolumn{2}{|c|}{$\begin{array}{c}\text { Normal } \\
\text { Over weight }\end{array}$} & Neonatal weight & & Total & $\mathbf{X}^{2}$ & $\mathbf{P}$ & $\begin{array}{c}\text { Kappa Agree- } \\
\text { ment }\end{array}$ \\
\hline \multirow{2}{*}{ Chol } & $<213.5$ & No. (\%) & $150(87.7)$ & $6(13.3)$ & $156(72.2)$ & \multirow{2}{*}{32.75} & \multirow{2}{*}{$0.00^{* *}$} & \multirow{2}{*}{0.66} \\
\hline & $>213.5$ & No. (\%) & $21(12.3)$ & $39(86.7)$ & $60(27.8)$ & & & \\
\hline \multirow{2}{*}{ HDL } & $>61.3$ & No. (\%) & $120(70.1)$ & $6(13.3)$ & $126(58.3)$ & \multirow{2}{*}{15.72} & \multirow{2}{*}{$0.00007^{* *}$} & \\
\hline & $<61.3$ & No. (\%) & $51(29.9)$ & $39(86.7)$ & $90(41.7)$ & & & 0.54 \\
\hline \multirow{2}{*}{$\mathrm{TG}$} & $<345$ & No. (\%) & $150(87.7)$ & $9(20)$ & $159(73.6)$ & \multirow{2}{*}{28.03} & \multirow{2}{*}{$0.00 * *$} & \multirow{2}{*}{0.61} \\
\hline & $>345$ & No. (\%) & $21(12.3)$ & $36(80)$ & $57(26.4)$ & & & \\
\hline \multicolumn{2}{|c|}{ Total } & No. (\%) & $171(79.2)$ & $45(20.8)$ & $216(100)$ & & & \\
\hline
\end{tabular}

The prevalence of LGA newborns was significantly higher in women with hypertriglyceridemia independent on BMI or maternal age. Maternal TG and cholesterol levels were significantly higher in the LGA group than in the AGA group (374.73 \pm 103.16$)$ vs (242.23 \pm 88.99$), \mathrm{p}=0.00$, and $(249.93 \pm 38.85)$ vs $(187.54 \pm$ $22.95) \mathrm{p}<0.0001$ respectively in contrast to HDL was significantly lower in the LGA group than in the AGA group (53.95 \pm 11.78$)$ vs. (66.61 \pm 9.01 ), $\mathrm{p}<0.0001$ (Table 4). Maternal Cholesterol, HDL-C and TG levels tended to be correlated with newborn birth weight with sensitivity $86.7 \%, 86.7 \%, 80 \%$ and specificity $87.7 \%, 70.1 \%$, $87.7 \%$, respectively (Table $5 \& 6$ ).

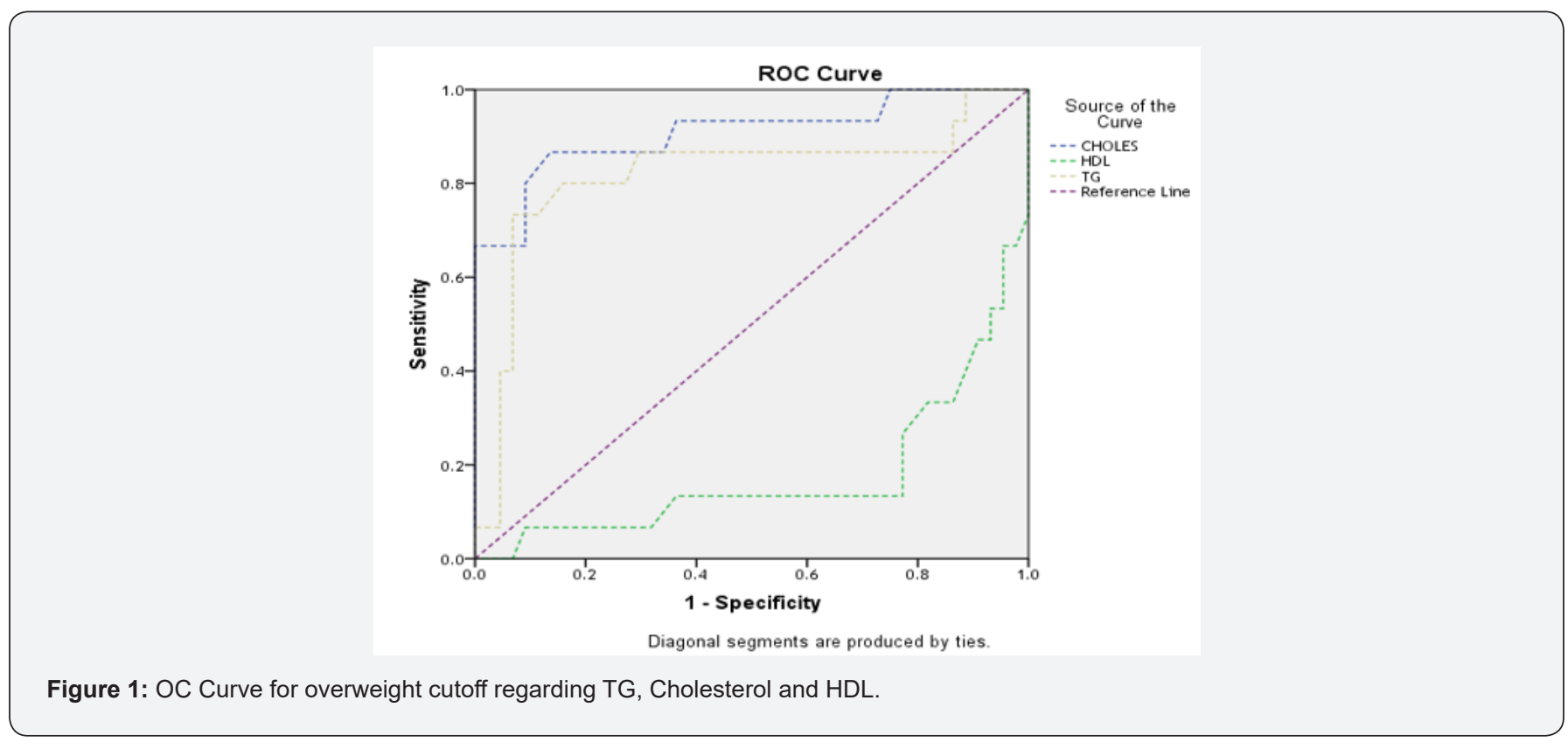


The area under the ROC curve was $0.817,0.832$ and 0.908 for maternal serum TG, HDL-C and cholesterol respectively in the prediction of LGA newborns. The optimally proposed cut-off values by the ROC analysis for maternal serum TG, HDL-C and cholesterol were $>345 \mathrm{mg} / \mathrm{dl},<61.3 \mathrm{mg} / \mathrm{dl}$ and $>213.5 \mathrm{mg} / \mathrm{dl}$ respectively. Maternal TG is a significant predictor of LGA newborns (95\% CI: $0.665-0.970$, cut off value $>345 \mathrm{mg} / \mathrm{dl}$, $\mathrm{p}<0.00$ ) with sensitivity and specificity of $80 \%$ and $87.7 \%$ respectively (Figure 1 ).

\section{Discussion}

In this prospective observational study on pregnant women with PGDM and GDM, we found maternal triglyceride, HDL-C, and cholesterol values in the third trimester of gestation were important predictors for macrosomia, independent of the maternal pregnancy BMI or maternal age. The current study showed that increase fetal weight, behind maternal glucose concentration is directly related to hyperlipidemia. Other studies demonstrated that maternal serum lipids are directly related to LGA, independent of maternal weight gain and glucose $[10,11]$. The increments of lipids during pregnancy mainly due to increments of estrogen [12]. The rising levels of estrogen with the advance of pregnancy reflects the changes in lipoproteins [8]. Lipids also increase with the increasing insulin resistance that presents in obesity, GDM and PGDM, as it was found in the studies of Gobi et al. [13], Kitajima et al. [14] and Knopp et al. [15]. Hyperlipidemia in diabetic pregnant women might also influence the fetal growth. In this study, we measured lipids in the third trimester in pregnant women with PGDM and GDM, there were higher levels of total cholesterol $(274.8 \pm 50.3 \mathrm{mg} / \mathrm{dl})$ in the type $1 \mathrm{DM}$ patients in comparison to that in the type $2 \mathrm{DM}(220.5 \pm 44.5 \mathrm{mg} / \mathrm{dl})$ and in GDM patients $(199.11 \pm 35.09 \mathrm{mg} / \mathrm{dl})$. Further, the multivariate analysis showed the positive relationship between the maternal cholesterol levels and the neonatal birth weight. Actually, the maternal cholesterol levels were an independent predictor for macrosomia. This agrees with Schaefer et al. [16], who found a positive correlation between the maternal cholesterol levels in the third trimester and the neonatal birth weight. Some studies have reported that serum lipids play an influential role in neonatal weight as compared to glucose level $[10,11]$.

Triglycerides level which showed continuous increase throughout pregnancy is the most frequently changed lipids in all studies [15]. The increase in the lipids metabolism is an adaptation of the increased fuel delivery to the fetus. When they are too high, macrosomic babies are more likely to be born. Mothers with type 2 DM had higher triglycerides levels $(286.83 \pm 58.85 \mathrm{mg} / \mathrm{dl})$ in comparison to the triglyceride levels in the type $1 \mathrm{DM}$ patients $(258.14 \pm 135.5 \mathrm{mg} / \mathrm{dl})$ and $(248.83 \pm 114.2)$ in GDM. Thus the triglycerides in late pregnancy were the strongest predictor of macrosomia. The increased triglycerides during the late pregnancy are due to the increased liver synthesis of VLDL under the effect of estrogens and increased adipose tissue lipolysis. HDL-C levels is reduced in type $1 \mathrm{DM}$ more than in type $2 \mathrm{DM}$ and GDM
$(61.33 \pm 7 \mathrm{mg} / \mathrm{dl})$ vs $(63.28 \pm 12.71 \mathrm{mg} / \mathrm{dl})$ and $(64.15 \pm 9.33 \mathrm{mg} /$ dl) respectively. In the study that was conducted by Yang et al. [17], a negative relationship was found between the HDL-C levels and the neonatal birth weight. In the present study, we stated that the negative relationship was found between HDL-C and LGA newborns ( $r=-0.0 .293, p=0.019$ ), but without independent influence on LGA. LDL-C levels were within the normal range in all studied groups.

Pusukuru et al. [18] found a significant increase in the cholesterol, triglyceride levels in the third trimester than in the second trimester. The mean cholesterol levels in third and second trimester were $(242.65 \pm 20.44 \mathrm{mg} / \mathrm{dl})$ and $(214.6 \pm 18.16 \mathrm{mg} / \mathrm{dl})$ respectively. The mean triglyceride levels in third and second trimester were $(216.78 \pm 20.09 \mathrm{mg} / \mathrm{dl})$ and $(188.68 \pm 20.88 \mathrm{mg} / \mathrm{dl})$ respectively. The mean HDL and Cholesterol levels in third and second trimester were $(43.07 \pm 4.34 \mathrm{mg} / \mathrm{dl})$ and $(49.13 \pm 6.15 \mathrm{mg} /$ dl) respectively.

The present study showed that overweight significantly higher regard TG and cholesterol in the third trimester but significantly lower regard TG and HDL-C in the second trimester. This agreed with findings of Wang et al. [19]. Hypertriglyceridemia was defined as more than the $75^{\text {th }}$ percentile value $(259 \mathrm{mg} / \mathrm{dl})$ of all subjects. The frequency of LGA infants was significantly higher in mothers with hypertriglyceridemia ( 4 of $34,12 \%$ ) than in mothers who had normal triglyceride levels (1 of 112, $0.9 \%$ ). Also agreed with an earlier study made by Kitajima M et al. [20] founded that the frequency of LGA infants was significantly higher in mothers with hypertriglyceridemia than in mothers who had normal triglyceride levels.

Also agreed with the results of Son et al. [21] from 104 women 25 delivered LGA newborns, 73 delivered appropriate-forgestational-age (AGA) newborns, and 6 delivered SGA newborns; SGA and AGA newborns were incorporated into the non-LGA group. Maternal TG levels were significantly higher in the LGA group than in the non-LGA group with median [283 (213-319) vs. 204(159-275), $p=0.001]$. Hypertriglyceridemia was defined as a TG level $>$ the $75^{\text {th }}$ percentile value $(>292 \mathrm{mg} / \mathrm{dl})$. The frequency of LGA newborns was significantly higher in women with hypertriglyceridemia than in those with normal TG levels [2 of $26,(46 \%)$ and 13 of $78,(4 \%)$, respectively; $p=0.02]$.

This also agreed with Cianni et al. [22] in 83 pregnant women with normal glucose tolerance (NGT) who delivered at term, the influence of lipid parameters on newborn weight was evaluated. The prevalence of LGA infants was significantly higher in women with hypertriglyceridemia $(\mathrm{P}<0.05) \quad\left(\mathrm{TG}\right.$ levels $>75^{\text {th }}$ percentile value; $204 \mathrm{mg} / \mathrm{dl}$ ) than in those with normal TG levels 4 of 19 (21\%) and 2 of 44 (4.5\%), respectively.

As shown in Area under Curve (AUC) for cholesterol=0.908, with (95\% CI: 0.804-1.000). AUC for HDL-C $=0.832$, with $(95 \% \mathrm{CI}$ : 
0.035-0.316). AUC for TG=0.817, with ( $95 \%$ CI: 0.665-0.970). This agreed with Son et al. The area under the ROC curve was 0.702 for maternal serum TG in the prediction of LGA newborns. The optimally proposed cut-off value by the ROC analysis for serum TG was $\geq 295 \mathrm{mg} / \mathrm{dl}$. Using that cut-off value, TG was a significant predictor of LGA newborns (95\% CI: 0.59-0.81; p=0.002) with sensitivity and specificity of 48.0 and $83.5 \%$, respectively [21]

Also agreed with Wang et al., the ROC curve was drawn to determine sensitivity and specificity for detecting the risk of delivering LGA newborns. The area under ROC curves of TG/HDL-C to detect LGA was 0.668 (95\% CI: 0.514-0.823). The optimal cutoff value proposed by the ROC analysis for TG/HDL-C was $1 \cdot 85$. Furthermore, the area under ROC curve to detect LGA was 0.806 (95\% CI, 0.719-0.893) [19]. The current study found a significant association and agreement between overweight cutoff regarding TG, Cholesterol, and HDL-C.

This study showed that TG is a considerable foreteller of neonatal weight. Forward stepwise logistic regression analysis showed that increased TG/HDL-C independently and highly associated with LGA infants which is compatible with the findings of Wang et al. [19] who applied a logistic regression model with confounding variables, including fasting levels of plasma glucose, pre-pregnant BMI, and gained weight during pregnancy, to test whether maternal hypertriglyceridemia foretells the risk of developing LGA infant at term, independent of fasting plasma glucose and maternal obesity. In the model, hypertriglyceridemia was an important foreteller of having an LGA infant at term (Odds ratio 11.6; 95\% CI: 1.1-1.22), independent of maternal glucose levels and obesity.

\section{Conclusion}

Measurement of maternal triglyceride level in the third trimester is an estimable foreteller of neonatal weight in women with diabetic pregnancy. However, large-scale studies are required to support this data.

High maternal TG concentrations in the third trimester were significantly related to an increased risk of fetal macrosomia in women with diabetic pregnancy. Additionally, the findings of our results focused the value of maternal lipid metabolism in impeding adverse maternal and neonatal outcomes.

\section{Recommendations}

Proper antenatal care for diabetic pregnant mothers is advised to achieve euglycemia and avoid abnormal increase in fetal weight during pregnancy. Follow up of serum triglyceride level is recommended to all women with diabetic pregnancy from $28^{\text {th }}$ weeks' gestation onwards. Pre-pregnancy care, early screening, appropriate management, planned delivery should be given to all women with diabetic pregnancy to minimize the risk of fetal macrosomia.

\section{References}

1. Horosz E, Bomba OD, Wielogos M, Szymanska M, Bartlkowink R, et al. (2009) Effects of maternal lipids on the fetal growth in gestational diabetes. Neuro Endocrinol Lett 30(5): 652-656.

2. Schaefer-Graf UM, Meitzner K, Ortega-Senovilla H, Graf K, Vetter K, et al. (2011) Differences in the implications of maternal lipids on fetal metabolism and growth between gestational diabetes mellitus and control pregnancies. Diabet Med 28(9): 1053-1059.

3. Son GH, Kwon JY, Kim YH, Park YW (2010) Maternal serum triglycerides as predictive factors for large-forgestational age newborns with gestational diabetes mellitus. Acta Obstet Gynecol Scand 89(5): 700704.

4. Sattar N, Greer IA (2002) Pregnancy complications and maternal cardiovascular risk: opportunities for intervention and screening. BMJ 325(7356): 157-160.

5. Vahratian A, Misra VK, Trudeau S, Misra DP (2010) Prepregnancy body mass index and gestational age-dependent changes in lipid levels during pregnancy. Obstet Gynecol 116(1): 107-113.

6. Koukkou E, Watts GF, Lowy C (1996) Serum lipid, lipoprotein and apolipoprotein changes in gestational diabetes mellitus: a crosssectional and prospective study. J Clin Pathol 49(8): 634-637.

7. Freinkel N (1980) Banting Lecture 1980. Of pregnancy and progeny. Diabetes 29(12): 1023-1035.

8. Barrett HL, Nitert MD, McIntyre HD, Callaway LK (2014) Normalizing metabolism in diabetic pregnancy: is it time to target lipids? Diabetes Care 37(5): 1484-1493.

9. Metzger BE (2010) International Association of Diabetes and Pregnancy Study Groups Consensus Panel. International Association of Diabetes and Pregnancy Study Groups recommendations on the diagnosis and classification of hyperglycemia in pregnancy. Diabetes Care 33(3): 676-682.

10. Simeonova KS, Krstevska B, Velkoska NV, Hagji-Lega M, Samargjiski I, et al. (2014) Effect of lipid parameters on foetal growth in gestational diabetes mellitus pregnancies. Pril (Makedon Akad Nauk Umet Odd Med Nauki) 35(2): 131-136.

11. Kulkarni SR, Kumaran K, Rao SR, Chougule SD, Deokar TM, et al. (2013) Maternal lipids are as important as glucose for fetal growth: findings from the Pune Maternal Nutrition Study. Diabetes Care 36(9): 27062713.

12. Smolarczyk R, Czajkowski K, Wójcicka-Jagodziñska J, Kostro I, Demkow $\mathrm{K}$, et al. (2001) The influence of chosen hormones on lipids and its correlation during normal pregnancy. Ginekol Pol 72(10): 765-771.

13. Gobi CS, Handisurya A, Klein K, Bozkurt L, Luger A, et al. (2010) Changes in serum lipid levels during pregnancy in type 1 and type 2 diabetic subjects. Diabetes Care 33(9): 2071-2073.

14. Kitajima M, Oka S, Yasuhi IFM, Rii Y, Ishimaru T, et al. (2001) Maternal serum triglyceride at 24-32 weeks' gestation and newborn weight in non diabetic women with positive diabetic screens. Obstet Gynecol 97(5 pt 1): 776-780.

15. Knopp RH, Magee MS, Walden CE, Bonet B, Benedetti TJ, et al. (1992) Prediction of infant birth weight by GDM screening: importance of triglyceride. Diabetes Care 15(11): 1605-1613.

16. Schaefer-Graf U, Graf K, Kulbacka I, Kjos SL, Dudenhausen J, et al (2008) Maternal lipids as strong determinants of fetal environment and growth in pregnancies with gestational diabetes mellitus. Diabetes Car 31(9): 1858-1863. 
17. Yang YD, Zhai GR, Yang HX (2000) Factors relevant to Newborn birth weight in pregnancy complicated with abnormal glucose metabolism. Zhonghua Fu Chan Ke Za Zhi 45(9): 646-651.

18. Pusukuruv R, Shenoi A, KumarKyada P, Ghodke B, Mehta V, et al. (2016) Evaluation of Lipid Profile in Second and Third Trimester of Pregnancy. J Clin Diagn Res 10(3): QC12-QC16.

19. Wang D, Xu S, Chen H, Zhong L, Wang Z, et al. (2015) The associations between triglyceride to high-density lipoprotein cholesterol ratios and the risks of gestational diabetes mellitus and large-for-gestational-age infant. Clin Endocrinol 83(4): 490-497.
20. Kitajima M, Oka S, Yasuhi IFM, Rii Y, Ishimaru T, et al. (2001) Maternal serum triglyceride at 24-32 weeks' gestation and newborn weight in non diabetic women with positive diabetic screens. Obstet Gynecol 97(5 pt 1): 776-780.

21. Son G, Kwon Y, Han Kim Y, Park YW (2010) Maternal serum triglycerides as predictive factors for large-for-gestational age newborns in women with gestational diabetes mellitus. Acta Obstet Gynecol Scand 89(5): 700-704.

22. Cianni GD, Miccoli R, Volpe C, Lencioni AG, Giovannitti I, et al. (2005) Maternal Triglyceride levels and newborn weight in pregnant women with normal glucose tolerance. Diabetic Med 22(1): 21-25.

\section{Your next submission with Juniper Publishers will reach you the below assets}

- Quality Editorial service

- Swift Peer Review

- Reprints availability

- E-prints Service

- Manuscript Podcast for convenient understanding

- Global attainment for your research

- Manuscript accessibility in different formats

( Pdf, E-pub, Full Tsext, Audio)

- Unceasing customer service

Track the below URL for one-step submission https://juniperpublishers.com/online-submission.php 